\title{
INDIVIDUACIÓN DE LAS TEORÍAS EN EL ENFOQUE SEMÁNTICO
}

\author{
GERMÁn GUERRERo PINO \\ Universidad del Valle
}

\begin{abstract}
This paper defends the idea that there are three determinant elements in the identity of theories in accordance with the semantic approach of theories: the kind of theoretic models, the data models and the empirical claims, but with some exceptions in each case. I uphold this thesis in an analysis the Structuralist view and van Fraassen's one about this respect.
\end{abstract}

\section{Introducción}

Existe un acuerdo generalizado, tanto entre defensores como entre detractores del enfoque semántico de las teorías científicas, ${ }^{1}$ en cuanto que el eslogan que mejor expresa la esencia del enfoque es que las teorías científicas quedan mejor comprendidas como conjuntos de modelos, en el sentido matemático abstracto, que como conjunto de enunciados. Así que la presente reflexión parte de reconocer que la caracterización de las teorías empíricas que hacen los semanticistas, en este sentido, recoge un aspecto esencial de la estructura de las teorías, pero al mismo tiempo asume como objetivo mostrar que dicho aspecto esencial no es único. En otras palabras, el presente trabajo presenta y sustenta una propuesta de solución a lo que se considera el problema de la individuación de las teorías, el cual entiendo en los siguientes términos: determinar los elementos clave que permiten identificar una teoría.

La tesis que se defiende, entonces, es que dentro del enfoque semántico de las teorías los elementos determinantes en la identidad de una teoría son la clase propuesta de modelos teóricos, los modelos de datos y las aserciones empíricas; ${ }^{2}$ pero con importantes salvedades en cada uno de estos elementos, como veremos más adelante. Para lograr lo anterior se ha elegido como estrategia de análisis y de exposición presentar lo que dicen al respecto las dos versiones más desarrolladas y conocidas del enfoque semántico, el estructuralismo (también conocido como concepción no-enunciativa) y la propuesta de van Fraassen (también conocida como concepción espacio de estados), destacando especialmente sus coincidencias en este punto.

Principia, 12(1) (2008), pp. 97-119. Published by NEL - Epistemology and Logic Research Group, Federal University of Santa Catarina (UFSC), Brazil. 


\section{Generalidades sobre los enfoques sintáctico y semántico ${ }^{3}$}

A la concepción de las teorías empíricas que entiende una teoría como principalmente un conjunto de enunciados se le llama concepción heredada, de acuerdo con Putnam, o concepción enunciativa, de acuerdo con Stegmüller, o enfoque sintácticoaxiomático (o para simplificar enfoque sintáctico), de acuerdo con van Fraassen, ${ }^{4}$ y actualmente contamos con una caracterización de este enfoque que podríamos calificar de estándar dada su gran aceptación por parte de los filósofos de la ciencia. De acuerdo con esta: dentro del enfoque sintáctico las teorías científicas se conciben como cálculos formales o sistemas formales axiomáticos parcialmente interpretados mediante reglas de correspondencia que relacionan términos teóricos con términos observacionales.

Podemos decir que, en el enfoque sintáctico, la geometría fue un paradigma en el análisis de la estructura de las teorías físicas y de las teorías empíricas en general. En este análisis los siguientes cuatro presupuestos fueron determinantes para intentar llevar a feliz término el programa: (1) las teorías empíricas son teorías matemáticas más una interpretación; (2) el lenguaje científico está compuesto por una parte observacional y otra teórica; (3) no es problemático dar razón de por qué los términos observacionales son significativos, mientras que sí lo es en el caso de los teóricos; y (4) una teoría es una entidad lingüística, un conjunto de enunciados.

También existe un amplio consenso en cuanto que la principal dificultad (para esta y otras dificultades que enfrenta el enfoque sintáctico, véase Suppe 1974, pp. 62-118 y Suppe 2000, p. 103) que enfrenta esta forma de caracterizar las teorías radica en lo que podemos llamar su dependencia lingüística, en implicar que las teorías son entidades lingüísticas. Es decir, en el gran compromiso lingüístico que adquiere ya que todo cálculo formal está asociado con un sistema sintáctico, se encuentra bajo el yugo de la sintaxis de un lenguaje. De modo que aquí la sintaxis no es algo secundario y aparece por tanto la siguiente tensión o contradicción en este enfoque: mientras que en la práctica científica es claro que podemos tener dos formulaciones de una misma teoría, si nos atenemos a los cánones de este enfoque, en especial a que hablar de formulaciones diferentes implica hablar de sintaxis diferentes (y, en últimas, de lenguajes diferentes), tenemos que concluir que las dos formulaciones equivalen a dos teorías distintas. Así, por ejemplo, desde el enfoque sintáctico las formulaciones lagrangiana y hamiltoniana de la mecánica clásica de partículas contarían como dos teorías distintas, pero sabemos que para los físicos esta situación es la de dos formulaciones distintas de una misma teoría.

Principia, 12(1) (2008), pp. 97-119. 
Precisamente la idea principal que defiende el enfoque semántico, enunciada en el eslogan de más arriba, se centra en criticar la dependencia lingüística del enfoque sintáctico y en presentar la forma como supera esta deficiencia asimilando una teoría con una entidad no lingüística, con un conjunto de modelos. Propongo entonces llamar a esta caracterización de las teorías "concepción semántica estándar" (para una presentación más completa de esta idea y la importancia de P. Suppes en este cambio de perspectiva, véase van Fraassen 1989, p. 222).

Pasemos ahora a los aspectos más importantes del estructuralismo y la concepción de van Fraassen. En cuanto al estructuralismo tenemos que principalmente son dos las obras consideradas una referencia clave del programa: una, el libro Logical Structure of Mathematical Physics (1971) de Joseph Sneed, que marca de algún modo el nacimiento del programa; y dos, la monumental obra conjunta An Architectonic for Science (1987), de Balzer et al., que podríamos considerar la obra madura del programa (véase Moulines 2002, p. 3). Además podríamos decir que el tema de la estructura de las teorías científicas es más dominante o recurrente en el programa estructuralista — que en la filosofía de van Fraassen- ya que es el eje central alrededor del cual giran sus otros temas de investigación, que desde luego tienen que ver directa o indirectamente con la estructura, simple y compleja, de las teorías. Entre estos temas cobran importancia: uno, asuntos relacionados con la estructura fina de las teorías tales como la determinación de diferentes tipos de relaciones intrateóricas e interteóricas, su formulación precisa en términos conjuntistas y la dinámica o evolución de las teorías; dos, la reconstrucción axiomática-conjuntista de teorías empíricas particulares; y tres, las conexiones de las teorías con la experiencia. Es decir, con las palabras del mismo C. U. Moulines, el estructuralismo "es esencialmente una teoría acerca de las teorías científicas - acerca de su identidad, estructura, relaciones mutuas y evolución” (Moulines 1996, p. 2).

Por otra parte, respecto a lo que tiene que ver con estrictamente la concepción de van Fraassen de la estructura de las teorías hay que decir que sus reflexiones enfocan los aspectos esenciales de las teorías - la estructura simple, para decirlo con las palabras de N. da Costa (véase da Costa 1997, p. 184)lo cual desde luego no es poco, pero podríamos decir que su análisis no tiene el grado de complejidad del de la concepción estructuralista. De modo que en este punto hay que reconocer que "el estructuralismo emplea un marco conceptual altamente diferenciado que le permite una representación extremadamente fina y graneada de la estructura (tanto sincrónica como diacrónica) de la ciencia, y que a la fecha no tiene precedente alguno en otro enfoque semejante" (Moulines 2002, p. 3).

Principia, 12(1) (2008), pp. 97-119. 
Si bien hay que reconocer lo anterior, también es cierto que van Fraassen ha hecho de su propia versión del enfoque semántico de las teorías (la concepción espacio de estados) un punto clave en el análisis que realiza de otros problemas filosóficos, de modo que sus temas de investigación son más variados que los del estructuralismo, pues por ejemplo tienen que ver con: distintas cuestiones en torno al realismo científico, haciendo de la polémica realismo-empirismo su campo de estudio más fecundo; la explicación en la ciencia, que junto con el anterior son de por sí temas generales de la filosofía de la ciencia; y ciertas cuestiones filosóficas ya clásicas y más particulares de determinadas teorías físicas: los problemas filosóficos del espacio-tiempo, la causalidad, las modalidades en la física, la probabilidad, determinados problemas filosóficos sobre la mecánica cuántica como su interpretación y su lógica.

\section{Concepción de van Fraassen: modelos teóricos y aserción empírica}

Creo que metodológicamente es más conveniente empezar presentando las generalidades de la propuesta de van Fraassen para después seguir con las del estructuralismo puesto que, como se dijo anteriormente, una de las peculiaridades de la primera propuesta, en contraste con la segunda, es que se concentra casi exclusivamente en los aspectos determinantes de la estructura de las teorías científicas. Ahora bien, aunque la concepción de van Fraassen trata la estructura simple de las teorías, nos encontramos con la dificultad de que sus planteamientos al respecto normalmente van acompañados de —o son empleados para- la defensa de su empirismo constructivo, una posición alternativa y opuesta al realismo. Por esto, y para comenzar, a continuación presento lo que considero es la formulación más simple de van Fraassen sobre estrictamente la estructura de las teorías, para después complementarla con otra formulación suya más compleja ya que involucra algunos aspectos relacionados con su empirismo constructivo.

Tal y como dice van Fraassen, en "la elegante y sintética formulación de Giere de la concepción semántica: presentar una teoría es definir un cierto tipo (o varios tipos) de sistemas más una o más hipótesis acerca de la relación de ciertos (tipos de) sistemas reales con la(s) clase(s) definida(s). Hablamos entonces de la definición teórica y de las hipótesis teóricas que conjuntamente constituyen la formulación de la teoría dada" (van Fraassen 1989, p. 226, y para la formulación de Ronald Giere véase Giere 1988, p. 85). Esta formulación da un paso adelante, respecto a lo que he dado en llamar la concepción semántica estándar,

Principia, 12(1) (2008), pp. 97-119. 
al proponer las hipótesis teóricas como un tipo de elemento adicional a la clase de modelos.

Veamos un ejemplo. Podríamos decir que tenemos una teoría al definir (o caracterizar) el conjunto de sistemas mecánicos newtonianos a través de las conocidas leyes de Newton de la mecánica y afirmar que nuestro sistema solar pertenece a este conjunto. Otra hipótesis teórica podría estar relacionada con la caída de los cuerpos sobre la Tierra y afirmar que cada uno de estos sistemas Tierra-cuerpo pertenece a la clase de sistemas definidos.

En otras palabras (y además con la idea de introducir expresiones un poco más neutrales con miras a emplearlas también cuando hablemos de la concepción estructuralista), la definición teórica proporciona una familia de modelos (de modelos teóricos) y una hipótesis teórica (que también podemos llamar aserción empírica) afirma que ciertos sistemas reales (modelos de datos) tienen determinada relación (identidad, aproximación, subsunción o subsunción aproximativa) con los modelos teóricos. Veamos cada una de estas partes por separado.

De acuerdo con van Fraassen, la forma como él emplea el término 'modelo' no tiene el sentido de la lógica o semántica formal. Coincide con la noción semántica de modelo (la de los lógicos) en que un modelo es básicamente una estructura (sistema) matemática(o) $\left\langle D, R_{i}\right\rangle$ en la que $D$ es un conjunto no vacío, llamado universo, y $R_{i}$ son una serie de relaciones definidas sobre este universo. Pero difiere en la condicional adicional que una estructura tiene que cumplir para ser un modelo en sentido semántico: una estructura es un modelo $\mathrm{M}$ de un enunciado ${ }^{5}$ e (o de un conjunto de enunciados) si la estructura satisface al enunciado (o a los enunciados) o, en otras palabras, si e es verdadero en M (véase Manzano 1989). Para van Fraassen "los modelos son estructuras matemáticas llamadas modelos de una teoría sólo en virtud de pertenecer a la clase definida de los modelos de esa teoría" (van Fraassen 1989, p. 366) y nada más, no hay ninguna dependencia lingüística o, mejor aún, sintáctica entre las estructuras definidas y los enunciados a través de los cuales se definen dichas estructuras. Además, la razón principal por la cual van Fraassen no equipara su uso de modelo con el de la semántica formal es porque "se perdería el impacto de la innovación de Suppes si los modelos se definen, como en muchos textos corrientes de lógica, como parcialmente entidades lingüísticas cada una bajo el yugo de una sintaxis particular" (van Fraassen 1989, p. 366).

Esto en cuanto a la clarificación de la noción de modelo, pero también es necesario decir algo más sobre la forma de presentar los modelos teóricos. En términos generales, una teoría presenta sus modelos teóricos a través de una relación de caracterización o una definición, pero no hay un acuerdo entre los partidarios Principia, 12(1) (2008), pp. 97-119. 
del enfoque semántico de las teorías empíricas en cuanto a la forma que la una o la otra deben tomar. Como se dejó ver en el ejemplo anterior de la mecánica newtoniana, las leyes newtonianas de la mecánica conforman una definición o una caracterización de una clase de modelos. Así pues, nos encontramos con que van Fraassen es partidario de definir o caracterizar los modelos a través de espacios-de-estados o, en el lenguaje de los físicos, espacios-de-fase (los cuales son una aplicación de los espacios de Hilbert de las matemáticas); esta perspectiva es especialmente notoria cuando aborda problemas filosóficos de la física. En tanto que, como veremos más adelante, el estructuralismo adopta como forma canónica la de definir los modelos mediante un predicado conjuntista.

¿Qué decir entonces de las aserciones empíricas, el otro tipo de componente de una teoría? Pero antes de hablar directamente de ellas, tenemos que decir algunas cosas relacionadas con lo que entiende van Fraassen por un sistema real, lo cual tienen que ver con la aserción empírica de una teoría, y también responder a por qué la necesidad de introducir este elemento adicional a los modelos teóricos en la identidad de una teoría. Aquí vale empezar por resaltar directamente que para van Fraassen un sistema real no es más que, en términos más gráficos y comunes, un fenómeno observable. Este asunto de caracterizar de un modo apropiado y preciso lo que se entiende por fenómeno observable es bastante delicado, objeto actualmente de importantes debates y críticas por parte de quienes rechazan el empirismo constructivo de van Fraassen; pero aquí sólo podemos presentar, por cuestión de espacio, los aspectos más importantes de su propuesta.

Para van Fraassen las teorías buscan, de un modo u otro y entre otras cosas, dar razón de la experiencia fenoménica que tenemos del mundo, y esta experiencia fenoménica, que es muy variada, es la que englobamos bajo la expresión "fenómenos observables". De acuerdo con van Fraassen el objetivo de las teorías científicas es salvar los fenómenos (salvar las apariencias), los cuales son de por sí observables. Ahora bien, en pocas palabras, para van Fraassen los fenómenos observables son, en general, los procesos y estructuras observables, los cuales específicamente dentro de la actividad científica pueden describirse mediante los informes experimentales y de medición. Y en este punto van Fraassen nos recuerda que "Patrick Suppes hace mucho tiempo enfatizó que las teorías no se contrastan con los datos brutos y crudos. Un reporte experimental ya es una representación selectiva y refinada, un "modelo de datos" como él los llama" (van Fraassen 1997, p. 523). Como puede verse, entonces, los fenómenos no remiten a experiencias sin ninguna elaboración o a resultados de observación completamente descontaminados o a cosas por el estilo.

Otro punto importante aquí tiene que ver con la distinción observable/inob-

Principia, 12(1) (2008), pp. 97-119. 
servable, la cual es bastante polémica debido a que para algunos no se puede trazar, en tanto que esta es una pieza clave dentro del programa de van Fraassen. Así que éste comienza por dejar claro que estas dos categorías se aplican a los objetos y eventos, en tanto que el otro par de categorías teórico/no-teórico — con las que en ocasiones incorrectamente se combinan las primeras - se aplica a las palabras o a los conceptos; por tanto, se comete un error categorial al hablar de, por ejemplo, términos observables o de objetos teóricos. Pero en concordancia con lo que se dijo sobre los fenómenos observables, el hecho de admitir dicha distinción no significa que esté defendiendo un fundamentismo (o realismo) ontológico, de acuerdo con el cual exista "un mundo prefabricado", por utilizar la expresión de Putnam; aunque, desde luego, podemos decir que el mobiliario del mundo es independientemente de nuestras conceptualización, ya que como el mismo van Fraassen dice: "los fenómenos son en principio observables por cualquiera, pero la forma de describirlos se elige, enseña y aprende por humanos que están completamente inmersos en su trasfondo heredado de las teorías, opiniones y suposiciones" (van Fraassen 1997, p. 524).

Pasando al otro punto que se anunció, vale preguntarnos: ipor qué es necesario añadir una o más hipótesis teóricas en la individuación de una teoría empírica? Para comenzar, el problema general ante el cual nos encontramos es el de explicar las actitudes epistémicas y doxásticas de los científicos hacia las teorías. Este tipo de actitudes las reconocemos a través de ciertas expresiones de conocimiento u opinión en las que los científicos atribuyen ciertas propiedades a las teorías que proponen, por ejemplo: ser verdaderas o falsas, creíbles o no creíbles, empíricamente adecuadas o no adecuadas, etc.; y es claro que la filosofía de la ciencia, en especial un análisis de las teorías, debería explicar este hecho.

Ahora bien, la concepción semántica estándar no da razón de estas actitudes al identificar las teorías con una clase de modelos ya que un modelo, una estructura, no puede ser objeto de una actitud doxástica o, con las palabras de van Fraassen, "una clase no puede ser verdadera o falsa. Así que la teoría tiene al menos que incluir algo más; por ejemplo, una afirmación o aseveración acerca de esta clase" (van Fraassen 1985, p. 26). De ahí que una teoría se identifique a través de una clase de modelos y una o varias aserciones empíricas que pretenden recoger las actitudes epistémicas o doxásticas de los científicos hacia las teorías. Esta última idea es clave para van Fraassen y la incluye, en los siguientes términos, como una de las tesis de su concepción semántica de las teorías: "una teoría es el tipo de cosa que puede ser verdadera o falsa, que puede describir la realidad correcta o incorrectamente y que creemos o no creemos" (van Fraassen 1989, p. 192).

Principia, 12(1) (2008), pp. 97-119. 
Finalmente abordemos el tema de la aserción empírica de una teoría. Dijimos que la forma general de cualquier aserción empírica es la de una relación entre un modelo teórico y un modelo de datos. Esta relación es de tipo estructural, puesto que los dos tipos de modelos son estructuras, de modo que en principio la relación podría ser una de las siguientes: isomorfismo, isomorfismo aproximativo, subsunción o subsunción aproximativa. Para comprender lo que piensa van Fraassen al respecto y sentar mejor algunas de las ideas ya expuestas, a continuación cito lo que considero la formulación más completa del punto de vista de van Fraassen sobre la estructura de las teorías científicas y que también contiene las ideas clave de su empirismo constructivo: "presentar una teoría es especificar una familia de estructuras, sus modelos; y en segundo lugar, especificar ciertas partes de esos modelos (las subestructuras empíricas) como candidatos para la representación directa de los fenómenos observables. Podemos llamar apariencias a las estructuras que pueden describirse en los informes experimentales y de medición. La teoría es empíricamente adecuada si tiene algún modelo tal que todas las apariencias son isomorfas con las subestructuras empíricas de ese modelo" (van Fraassen 1980, p. 64).

Un primer punto que salta aquí a la vista es que no se dice nada sobre las hipótesis teóricas. Esta cuestión la podemos dejar de lado por ahora, pero será de gran interés más adelante cuando abordemos los planteamientos de Pérez Ransanz sobre la concepción de las teorías de van Fraassen. Por otra parte, la noción nueva e importante aquí es la de adecuación empírica, que contrasta con la de verdad, otra noción también importante. La relación de adecuación empírica es un isomorfismo entre una subestructura empírica (esto es, una subestructura de uno de los modelos teóricos propuestos) y un modelo de datos (una apariencia), en tanto que creer que una teoría es verdadera es creer que uno de los modelos teóricos propuestos es isomorfo con la realidad. Como ya se había insinuado antes, para van Fraassen el objetivo de la actividad ciencia es proporcionarnos teorías empíricamente adecuadas y no propiamente verdaderas, un objetivo que él considera pretencioso e inviable. Esta tesis constituye el sello distintivo de su empirismo constructivo en contraposición al realismo. ${ }^{6}$

Llegados a este punto es necesario establecer una distinción entre consideraciones estructurales y consideraciones epistemológicas con miras a poder delimitar (esto precisamente se hace al final de este numeral y del último) aquellos elementos determinantes en la individuación de las teorías, los cuales creo han de apuntar de manera exclusiva a cuestiones puramente estructurales en el análisis de las teorías. De acuerdo con van Fraassen la concepción semántica es epistemológicamente neutral respecto al debate realismo-empirismo y esto porque dichas

Principia, 12(1) (2008), pp. 97-119. 
posiciones no hacen parte de la propuesta ya que esta sólo afirma que existe una relación entre la clase de modelos teóricos y ciertos modelos de datos sin comprometerse con un tipo específico de relación. Cosa, esta última, que sí hacen las posturas epistemológicas del realismo y el empirismo.

Aún siendo esto así, lo cual es muy importante, considero que existe otro punto en el que se involucran consideraciones epistemológicas. Este tiene que ver con la caracterización de lo que podemos llamar en términos genéricos "la experiencia", la cual van Fraassen describe en términos observables y, como veremos a continuación, el estructuralismo en términos T-no-teóricos. En otras palabras, esto significa caracterizar de una forma u otra los modelos de datos (la experiencia fenoménica) y por tanto, en últimas, arriesgan una propuesta sobre determinado aspecto de la evaluación de las teorías empíricas, cuestiones estas que considero pueden calificarse correctamente de epistemológicas. Las implicaciones de esto último se verán al final del presente escrito.

Para terminar, en qué términos respondería van Fraassen a icuáles son los elementos que permiten identificar una teoría empírica? A la luz de lo estrictamente dicho, considero que diría (y de este modo es como corrientemente se interpreta su postura) que estos elementos son dos: los modelos teóricos y las aserciones empíricas. En este punto mi propuesta es que esto es así si nos atenemos únicamente a la letra, ya que me parece que hay un tercer elemento implícito en la caracterización de van Fraassen, pero que ha estado presente en toda esta discusión de un modo explícito: los modelos de datos. Los modelos de datos están implícitos al proponer que una aserción empírica es un segundo elemento de identidad y al caracterizarla como una relación entre un modelo teórico y un modelo de datos. Por tanto, sería más adecuado identificar las teorías empíricas a través de tres elementos clave: los modelos teóricos, los modelos de datos y las aserciones empíricas.

Me parece que A. R. Pérez Ransanz no estaría de acuerdo con mi lectura de la propuesta de van Fraassen en la que planteo que es compatible con introducir los modelos de datos (los fenómenos observables) como un tercer elemento de la identidad de una teoría. Esto porque Pérez Ransanz plantea que "según van Fraassen el tipo de fenómenos que la teoría pretende subsumir bajo sus modelos, no forma parte constitutiva de la teoría" (Pérez Ransanz 1985, p. 12). Esta idea la obtiene del análisis que realiza van Fraassen de los logros no esperados y al final del cual se pregunta y responde: "esto indica que la determinación de qué tipo de fenómenos han de encajar en qué tipo de subestructuras empíricas se vuelve parte de la teoría. No creo que esto sea necesario. Los logros no esperados desaparecen cuando miramos partes observables más grandes del mundo; digamos, cuando

Principia, 12(1) (2008), pp. 97-119. 
miramos simultáneamente la óptica y la mecánica de las fuentes luminosas en movimiento" (van Fraassen 1980, p. 66).

Para comenzar, creo que la interpretación que hace Pérez Ransanz de estos pasajes de van Fraassen es correcta y por tanto concluyo que esta afirmación de van Fraassen se debe a que sostiene una concepción semántica estándar de las teorías en la que una teoría empírica se identifica con su clase de estructuras. Esta conclusión parece extraña, pues no es acorde con lo que venimos diciendo sobre la propuesta de van Fraassen, especialmente con su idea de que proponer una teoría es proponer un conjunto de estructuras y varias hipótesis. Pero parece que esta conclusión es correcta ya que el mismo van Fraassen presenta este análisis de los logros no esperados y su ilustración de las condiciones de unicidad y universalidad como dos casos de aplicación exitosa de la concepción estándar de Suppes. Esto también lo reconoce Pérez Ransanz pues a continuación de lo anterior dice que "van Fraassen, al igual que Suppes, parece creer que la estructura de una teoría empírica, en tanto teoría, no es esencialmente diferente de la estructura de una teoría de la matemática pura" (Pérez Ransanz 1985, p. 12).

Así que nos encontramos con un cambio importante en el punto de vista de van Fraassen sobre las teorías empíricas. Este cambio consiste en introducir las hipótesis teóricas como una componente más —adicional a la clase de modelosde las teorías científicas. De acuerdo con mi documentación, esto sucedía entre la publicación The Scientific Image (1980) y la respuesta de van Fraassen (1985) al escrito El concepto de teoría empírica según van Fraassen (1985) de Pérez Ransanz. Por tanto, considero que lo que podríamos calificar como objeción de Pérez Ransanz no afecta a mi idea de que introducir los modelos de datos como un tercer elemento de la identidad de una teoría es relativamente compatible con los planteamientos de van Fraassen, ya que aquí nos referíamos concretamente a sus planteamientos después del cambio.

Aún más, creo que las siguientes palabras de van Fraassen, que pertenecen a su respuesta de 1985, dan más peso a la tesis que estoy proponiendo: "está claro que en la hipótesis teórica se identifican o por lo menos se mencionan ciertas partes específicas del mundo, y que esto puede ser diferente para dos teorías, incluso si la definición teórica es la misma” (van Fraassen 1985, p. 27). En escritos suyos más recientes encontramos ejemplos de este tipo que buscan ilustrar "el carácter intencional de la representación”, de acuerdo con la concepción representacional que presupone el enfoque semántico; el ejemplo es éste, "la misma curva exponencial podría ser la curva de dos modelos de datos, uno el crecimiento de una población de bacterias y el otro el decaimiento radioactivo. Pero los datos extraídos de una muestra de radio no son relevantes para una teoría acerca

Principia, 12(1) (2008), pp. 97-119. 
de las bacterias. Simplemente es irrelevante que un modelo de datos obtenido en el estudio de la radioactividad esté por consiguiente estructuralmente relacionado con un modelo de población de bacterias, incluso si en este respecto no hay diferencias con lo que encontramos en los experimentos bacteriológicos (van Fraassen 1997, p. 524).

De modo que en algún sentido una teoría delimita el tipo de fenómenos que pretende subsumir en sus modelos teóricos. Aunque es claro que esta delimitación no se hace por medio de estipulaciones formales o cosas semejantes sino principalmente a través de "los parámetros relevantes de la teoría". Estos parámetros tienen que ver, en términos del ejemplo anterior, en un caso con bacterias y su comportamiento, y en el otro con elementos radioactivos y su comportamiento. En términos más generales, "los modelos en la ciencia — plantea van Fraassen- son usados para representar la naturaleza, usados por nosotros, y entre los muchos modos posibles de usarlos, el modo actual es muy importante y fija la relación relevante entre el modelo y la naturaleza - esto es, relevante tanto para la evaluación como para la aplicación de la teoría" (van Fraassen 1997, p. 523).

Ahora bien, con la propuesta que estoy haciendo se quiere dar un paso adelante ya que, para el caso, lo que se está planteando es que la mejor forma de explicitar este tipo de delimitación borrosa es incluyendo el conjunto de fenómenos en la teoría. Esta es una idea que defiende bastante bien el estructuralismo, aunque también hay cierta diferencia con lo que yo estoy planteando, como veremos a continuación. Dicho de otro modo, considero que la concepción estructuralista también respalda la tesis que aquí se está defendiendo aunque, hay que decirlo, no de manera explícita sino de una forma muy semejante a como vimos lo hace la concepción de van Fraassen.

\section{Estructuralismo: núcleo teórico y aplicaciones intencionales}

Con la intención de hacerle justicia parcialmente a la propuesta estructuralista en lo que tiene que ver con el análisis detallado y profundo que encierra, y a sabiendas de que aquí dicho análisis no va a tenerse en cuenta en toda su complejidad sino en lo que hemos calificado como la estructura simple de las teorías científicas, a continuación presento lo que considero la mejor caracterización, en forma sucinta, que hace el estructuralismo de la noción de teoría: "la clase más simple de estructuras que podemos emplear para decir algo acerca del mundo es una estructura compuesta de un núcleo $K$ y su correspondiente dominio de aplicaciones intencionales I. El par $\langle K, I\rangle$ es lo que llamamos elemento teórico." (Moulines 2002, p. 8)

Principia, 12(1) (2008), pp. 97-119. 
Por tanto, en el presente estudio sólo tendremos en cuenta la noción de elemento teórico puesto que aquí, nuevamente, únicamente estamos interesados en clarificar los aspectos determinantes en la identidad de una teoría y además, como bien puede apreciarse en la cita, esta es la noción clave en el análisis estructuralista. Esta noción es básica en dos sentidos: de ella dependen otras nociones importantes introducidas por los estructuralistas en el análisis de las teorías y, en dicho análisis, un elemento teórico es la unidad más pequeña que de por sí proporciona información sobre el mundo.

Ahora bien, de acuerdo con los estructuralistas, el núcleo (teórico) $\mathrm{K}$ es la parte formal del elemento teórico $T=\langle K, I\rangle$ (o teoría, para el presente estudio) y el campo de aplicaciones intencionales $I$ es la parte aplicativa de $T$. A grandes rasgos, se habla de parte formal porque el núcleo contiene diferentes elementos conceptuales y las leyes que rigen su objeto de estudio, y de parte aplicativa porque, como su nombre lo indica, los sistemas reales, empíricos, a los cuales se pretende aplicar las leyes de la teoría pertenecen al conjunto de aplicaciones intencionales. En los términos del ejemplo de la mecánica newtoniana, propuesto más arriba, tenemos que: por una parte, el núcleo teórico está relacionado con la definición a través de las conocidas leyes de Newton de la mecánica y, hablando estrictamente, equivale al conjunto de sistemas mecánicos newtonianos determinados por dicha definición; y, por otra parte, nuestro sistema solar y cada uno de los sistemas Tierra-cuerpo (que ilustran la caída de los cuerpos) son, en sentido estricto, aplicaciones intencionales de la mecánica newtoniana, es decir, cada uno de estos sistemas pertenece al conjunto $I$.

Por tanto, esta pequeña ilustración nos permite establecer, grosso modo, el siguiente paralelo entre los términos estructuralistas y la terminología que venimos utilizando: "núcleo teórico" con "conjunto de modelos teóricos" y "aplicación intencional" con "modelo de datos". La cuestión interesante que surge es la de si podemos establecer las correspondientes equivalencias. Como veremos en lo que sigue, la primera equivalencia no es problemática en tanto que la segunda sí lo es. La última equivalencia es problemática en la medida en que considero que hay por lo menos una discrepancia importante en este punto entre el estructuralismo y la concepción de van Fraassen. Discrepancia que no es meramente terminológica -ya que ambos puntos de vista estarían de acuerdo en hablar indistintamente de modelos de datos o aplicaciones intencionales- sino de contenido, ya que la caracterización general de lo que es un modelo de datos (o una aplicación intencional) difiere de una concepción a otra: mientras van Fraassen hace la caracterización en términos de "observables", los estructuralistas la hacen en función de "términos T-no-teóricos".

Principia, 12(1) (2008), pp. 97-119. 
Veamos la primera equivalencia. La cuestión tiene que ver con cómo presenta el estructuralismo el conjunto de modelos teóricos (el núcleo teórico). Ya habíamos adelantado que lo hacía a través de una definición en términos de un predicado conjuntista (véase Moulines 2002, p. 6) en la que la forma canónica de la definición es: " $x$ es un modelo de la teoría ... syss $_{\operatorname{def}} \varphi(x)$ ", donde $\varphi$ expresa principalmente las leyes de la teoría. Ahora bien, aunque existe una diferencia importante entre estas dos versiones del enfoque semántico — la de van Fraassen y la estructuralista-en cuanto a la forma de presentar los modelos teóricos de una teoría, ya que la primera los describe mediante un espacio de estados y la segunda mediante el instrumental de la teoría de conjuntos, lo cierto es que esta no se considera importante porque en últimas tenemos dos formas distintas de describir las mimas estructuras. En este punto comparto el punto de vista de F. Suppe, cuando dice que "una cuestión digna de investigarse es cuán significativa son estas diferencias; mi conjetura es que estas reflejan más las preferencias matemáticas de los autores o decisiones sobre qué enfoque matemático es el más indicado para progresar en otros problemas filosóficos en los que el autor está interesado y no desacuerdos filosófico significativos entre ellos" (véase Suppe 1989, p. 420).

Para terminar esta parte relacionada con los modelos teóricos (o núcleo teórico) quisiera hacer una sutil e interesante observación sobre la noción de modelo en el estructuralismo. Considero que el estructuralismo no es suficientemente claro en este punto, puesto que, en los mismos términos que planteamos esta cuestión para el caso de van Fraassen, hay afirmaciones en las que los estructuralistas dan a entender que un modelo teórico es un modelo semántico, y valga reiterar que la noción de modelo en la semántica formal es muy precisa, aplicable únicamente en aquellos casos donde se cuenta con un lenguaje formal. Así, por ejemplo, Moulines plantea que "tales complejos conocidos como teorías consisten en modelos en el sentido de la semántica formal, es decir, en estructuras que satisfacen un conjunto dado de axiomas" (Moulines 1991a, p. 316). En tanto que en otras ocasiones ponen de relieve que el tipo de lenguaje empleado por las ciencias empíricas no puede reducirse en absoluto a un lenguaje formal (véase, por ejemplo, Moulines 2002, p. 6).

Creo que la supuesta confusión en la que cae el estructuralismo radica en que si bien es cierto que podemos decir que un modelo teórico satisface ciertos enunciados o axiomas (aquellos que permiten describir o identificar el conjunto de modelos al cual pertenece), hay que tener claro que el sentido aquí de "satisface" es trivial y no técnico, es decir, no se acoge estrictamente a los cánones de la lógica. Y esto porque, estrictamente hablando, no cabe hablar de modelo semántico

Principia, 12(1) (2008), pp. 97-119. 
(en el sentido de la semántica formal) fuera de un lenguaje formal y porque las teorías empíricas, como lo reconoce el estructuralismo, no pueden axiomatizarse dentro de un lenguaje formal.

Por tanto, considero que si nos atenemos más al espíritu que a la letra de los planteamientos del estructuralismo, podemos concluir que en últimas los estructuralistas no estarían de acuerdo con equiparar el uso de modelo teórico con el de modelo semántico, coincidiendo así con lo que van Fraassen piensa al respecto. Aún más, otra razón que me lleva a esta conclusión es que el estructuralismo también comparte la idea de que el conjunto particular de enunciados (un lenguaje particular) a través de los cuales se presenta una teoría tiene una función secundaria en la identidad de una teoría.

Pasemos ahora a la noción de aplicación pretendida o intencional (intended application). Para comenzar, ipor qué la concepción estructuralista introduce las aplicaciones intencionales como un elemento más en la identidad de las teorías? Se mencionan varias razones, pero ninguna de ellas tiene que ver directamente con la cuestión de la posibilidad de aplicar la noción de verdad a las teorías empíricas, como en el caso de van Fraassen. De cualquier manera, valga decir, en el estructuralismo también se aborda y resuelve esta cuestión pero en otros términos (tal como veremos más adelante), de modo que no cabe decir que el estructuralismo cae en el instrumentalismo.

En concreto, si identificamos una teoría empírica con únicamente un núcleo teórico, con un conjunto de estructuras descritas en términos puramente formales, no podríamos en principio diferenciar esta teoría de una teoría matemática pura. Por tanto, la teoría debe contener algo más (un conjunto de aplicaciones intencionales) que haga referencia al mundo o, más precisamente, al dominio al cual se pretende aplicar, el cual sólo puede describirse en términos informales. La inclusión del conjunto de aplicaciones intencionales dentro de los elementos de identidad de una teoría, puede ilustrarse mediante el siguiente ejemplo de Moulines que es bastante gráfico: "podemos saber muchas cosas acerca de la estructura de un martillo, pero si no sabemos que puede servir para clavar clavos, no tendremos una comprensión cabal de lo que es un martillo; al concepto de martillo pertenece, entre otras cosas, el que se use para clavar clavos" (Moulines 1991b, p. 279).

El estructuralismo también estaría de acuerdo con que las teorías empíricas buscan, de un modo u otro y entre otras cosas, dar razón de la experiencia fenoménica que tenemos del mundo. Así, por ejemplo, Moulines plantea que "lo esencial de una teoría empírica consiste precisamente en el hecho de que sus principios tienen que aplicarse supuestamente a los fenómenos, que son "exter-

Principia, 12(1) (2008), pp. 97-119. 
nos" a estos, de un modo tal que sea posible hacer explicaciones, predicciones y aplicaciones tecnológicas. A este "mundo exterior", el estructuralismo lo llama "el dominio de aplicaciones intencionales": este es el campo de fenómenos a los que la gente, a través de la teoría, pretende aplicar sus conceptos y leyes" (Moulines 1996, p. 8). Pero con lo que no estaría de acuerdo, digámoslo de una vez, es con calificar los fenómenos de "observables", en un sentido claro e interesante, filosóficamente hablando. Es decir, el estructuralismo también habla en términos de "experiencia fenoménica", "fenómenos" y "datos" — expresiones todas ellas que, para el presente caso, podemos considerar equivalentes-y además plantea que "las aplicaciones intencionales representan los fenómenos con los que una teoría trata" (Balzer y otros 1987, p. 86), pero no caracteriza las experiencias fenoménicas en función de "observables" (como hace van Fraassen) sino más bien, como ya adelantábamos, en función de "términos T-no-teóricos". Veamos esto más detenidamente.

De acuerdo con el estructuralismo, las principales peculiaridades de las aplicaciones intencionales tienen que ver con cómo concebir (describir, conceptualizar) una aplicación intencional dentro de una teoría dada y cuál es la extensión del conjunto de aplicaciones intencionales (Moulines 1991a, p. 319). A la segunda cuestión el estructuralismo responde que realmente dicha extensión no puede fijarse de un modo preciso ya que en su determinación intervienen no sólo medios formales (semánticos) sino también consideraciones pragmáticas y diacrónicas. Esto último porque las aplicaciones no pueden desligarse de los usuarios de las teorías, especialmente de las comunidades científicas, y de ciertos factores históricos (véase Moulines 1991b, p. 282).

Creo que esta última conclusión me permite hacer una aclaración sobre un aspecto puntual sobre el estudio de la individuación de las teorías científicas, el cual de algún modo ha estado todo el tiempo implícito pero que igualmente vale la pena enunciar en forma directa. Al comienzo dije que el problema de la individuación de las teorías tenía que ver con "determinar los elementos clave en la identificación de una teoría", así que aquí no se trata de encontrar la esencia de una teoría o algo por el estilo, sino simplemente de ubicar ciertas características de las mismas que podríamos considerar como invariantes. Aún así, nos encontramos con dos tipos de ambigüedades a la hora de pretender identificar una teoría: una tiene que ver con el tipo de elementos que nos permiten identificarla y la otra con, una vez elegido un elemento, la imposibilidad de determinarlo en una forma exhaustiva. El primer tipo de ambigüedad lo describe bastante bien Moulines, "las teorías científicas son entidades de tipo genidéntico (son cosas que cambian continuamente), pero de ello no podemos inferir que es imposible

Principia, 12(1) (2008), pp. 97-119. 
identificarlas o distinguir un espécimen de otro del mismo tipo ... Las teorías científicas son cosas dadas empíricamente y, al igual que tantas otras cosas dadas empíricamente en este mundo no demasiado platónico, hay que admitir cierto grado de vaguedad o de traslape en su determinación" (Moulines 1991b, p. 216).

El segundo tipo de ambigüedad aparece tanto en la determinación de los modelos teóricos como en la de las aserciones empíricas y los modelos de datos. La ambigüedad en los modelos de datos (en las aplicaciones intencionales) es la que acabamos de comentar, respecto a las otras Giere plantea que "la teoría científica resulta no ser una entidad definida. Es decir, que no hay condiciones necesarias y suficientes que determinan qué modelos o qué hipótesis son parte de la teoría” (Giere 1988, p. 86).

Volviendo ahora a la primera cuestión, tenemos que una aplicación no está dada independientemente de una conceptualización, sino que su descripción se da mediante un aparato conceptual. Esto es, el dominio de aplicaciones intencionales "no es ni 'realidad pura' ni 'pura experiencia' — signifiquen lo que signifiquen estas expresiones" (Moulines 1996, p. 8), sino que una aplicación intencional se determina conceptualmente mediante — en terminología estructuralista"el aparato conceptual de la teoría" y mediante conceptos ya disponibles, los cuales son externos a la teoría en cuestión.

Esto es, de acuerdo con el estructuralismo, los conceptos empleados por una teoría $T$ pueden dividirse en conceptos teóricos y no-teóricos, no en sentido absoluto sino respecto a $T$; esto es, $T$ tiene conceptos $T$-teóricos y conceptos $T$ no-teóricos. Los primeros son conceptos introducidos específicamente por $T$, de modo que su significado viene determinado exclusivamente por $T$; y los segundos son conceptos no específicos de $T$ y su significado está completamente determinado por teorías previas a, y subyacentes a, T. Así que, de manera más precisa, no sólo se mantiene que, dada una teoría $T=\langle K, I\rangle$, los elementos de $I$ han de concebirse en términos de la estructura conceptual de $K$, es decir, en términos de las caracterizaciones o tipificaciones de los axiomas "impropios", sino además se plantea que tienen que describirse mediante conceptos T-no-teóricos.

Aún más, entiendo que el campo de aplicaciones intencionales de una teoría $T$ es parte importante de la "base empírica" de T. Esto porque, de acuerdo con los estructuralistas, la base empírica es "un cuerpo de conceptos por medio del cual la teoría puede ser controlada o por medio del cual podemos averiguar cuándo la teoría funciona correctamente y cuándo no" (Balzer y otros 1987, p. 48) y además, como ya vimos, el dominio I se determina mediante términos T-no teóricos. En síntesis, las aplicaciones intencionales de una teoría tienen un papel importante en la evaluación empírica de la misma.

Principia, 12(1) (2008), pp. 97-119. 
Esto último se observa muy bien si nos fijamos en la forma que la concepción estructuralista da a la aserción empírica de una teoría; así, por ejemplo, Moulines plantea que, para una teoría $T=\langle K, I\rangle$ dada, "la aserción empírica de la teoría es el siguiente enunciado global: el dominio de aplicaciones intencionales I puede subsumirse en K" (Moulines 2002, p. 8); esto es, que los principios de la teoría pueden aplicarse correctamente a los sistemas empíricos descritos en I. Esto último es muy importante porque aquí no sólo constatamos que I conforma la base de contrastación de $T$ sino que también nos encontramos con un nuevo elemento en juego (la aserción empírica) que tiende un puente entre I y $K$, siendo esta la forma como los estructuralistas recuperan las actitudes doxásticas de los científicos. De esta manera y en estos términos, el estructuralismo sería incompatible con una interpretación instrumentalista de las teorías científicas.

Aún más, podemos decir que la concepción estructuralista de las teorías es epistemológicamente neutral respecto al debate realismo-antirrealismo, tal y como este está formulado por van Fraassen. Es neutral en el sentido que sus planteamientos no abogan por una interpretación realista o empirista de las teorías. Dicho debate queda abierto aquí. Pero aún siendo esto así, considero que hay un sentido en que no es neutral epistemológicamente, el mismo sentido en que la concepción de van Fraassen no lo es. Esto porque, como ya había adelantado, la distinción de van Fraassen observable/inobservable y la de la concepción estructuralista $T$-no-teórico/T-teórico son distinciones que caracterizan de una forma u otra los modelos de datos (la experiencia fenoménica) y por tanto, en últimas, arriesgan una propuesta sobre determinado aspecto de la evaluación de las teorías empíricas, cuestiones estas que considero pueden calificarse correctamente de epistemológicas.

¿Cuál de estas dos perspectivas es la más adecuada a la hora de caracterizar los fenómenos, los modelos de datos? ¿Qué otras alternativas se tienen al respecto y qué tan apropiadas son? Estas preguntas quedan aquí abiertas en la medida en que arriesgar una respuesta involucra muchos más elementos y argumentos de los hasta ahora presentados.

Para terminar, en qué términos responde la concepción estructuralista a ¿cuáles son los elementos que permiten identificar una teoría empírica? En estos, "el estructuralismo dice que aunque conozcáis $K$, y por tanto podáis identificar la teoría, no conocéis todo lo que hay que conocer acerca de esta como teoría empírica, a menos que también conozcáis, hasta cierto punto, cómo se presentan las aplicaciones intencionales de K" (Moulines 1991a, p. 319). Para comenzar, la presente respuesta no es la misma que da van Fraassen. Podemos estar de acuerdo en que las dos versiones coinciden en que la clase de modelos teóricos es

Principia, 12(1) (2008), pp. 97-119. 
uno de los dos elementos de identidad de una teoría científica y también en que discrepan en cuanto al segundo elemento: para van Fraassen es el conjunto de aserciones empíricas y para la concepción estructuralista el conjunto de aplicaciones intencionales. En este punto me parece interesante presentar lo que opina A. R. Pérez Ransanz al respecto, ya que llega a un resultado semejante al anterior, pero a partir del cual concluye algo que no comparto: "a mi juicio, la propuesta estructuralista ofrece las siguientes ventajas frente a la propuesta de van Fraassen. La inclusión de la aserción empírica en la identidad de una teoría —como hace van Fraassen siguiendo a Ronald Giere- nos deja con un compuesto ontológicamente híbrido. Esto es, con un compuesto donde ciertos elementos no son candidatos a tener un valor de verdad, los modelos, mientras que otros sí lo son, las "hipótesis teóricas". Por tanto, resulta más limpio, desde un punto de vista ontológico, identificar las teorías con entidades que sean todas de la misma naturaleza" (Pérez Ransanz 2000, p. 113).

Mi objeción es que estas diferencias que se aprecian a primera vista, y que Pérez Ransanz describe bastante bien, son simplemente cuestión de presentación, de forma, más no de contenido. Esto porque al final del numeral anterior mostré que en la propuesta de van Fraassen realmente son tres los elementos en juego y porque, si bien es cierto que en la caracterización que hace la concepción estructuralista son dos los elementos presentes en forma explícita, me parece que hay un tercer elemento implícito en dicha caracterización, el cual se hizo explícito al final de la presentación de la concepción estructuralista: la aserción empírica de la teoría. El conjunto de aserciones está implícito al proponer, por una parte, las aplicaciones intencionales como una segunda componente de las teorías y al plantear, por otra parte, que estas están de algún modo vinculadas con el núcleo teórico. Más exactamente, al plantear que las aplicaciones tienen que estar descritas en términos del aparto conceptual de la teoría y mediante conceptos T-no-teóricos.

Aún más, considero que Diederich, otro filósofo de la ciencia que ha realizado estudios comparativos de estas dos concepciones, compartiría esta idea que estoy proponiendo sobre la importancia de la aserción empírica dentro la concepción estructuralista y que considero Pérez Ransanz no le da la importancia que merece en la identidad de una teoría dentro del estructuralismo. Diederich dice que las dos concepciones "comparten la forma lógica que toma la aserción asociada con una teoría, la forma de un enunciado existencial. En el caso de van Fraassen, una teoría asevera sobre un fenómeno dado que es (isomorfo con) una subestructura de uno de los modelos de la teoría, y también asevera que todos los fenómenos relevantes encajan en uno y el mismo modelo. De acuerdo con la concepción

Principia, 12(1) (2008), pp. 97-119. 
estructuralista, la forma básica de la aserción de una teoría es que una estructura no-teórica (un modelo potencial parcial de la teoría) se puede expandir a un modelo completo de la teoría y que conjuntamente todas las aplicaciones intencionales también satisfacen ciertas restricciones" (Diederich 1996, p. 18).

Aquí se coloca de relieve que las dos concepciones no sólo admiten la importancia de la aserción empírica en una teoría empírica, sino que también coinciden en la forma lógica que esta tiene, el tipo de relación estructural entre (en términos neutrales) modelos de datos y modelos teóricos. Aspecto este último que me parece Pérez Ransanz tampoco tiene en cuenta. Además de las similitudes anteriores, existe otra digna de destacarse: la condición de unicidad. ${ }^{?}$

Por tanto, reitero que sería más adecuado identificar las teorías empíricas a través de tres elementos: los modelos teóricos, los modelos de datos y las aserciones empíricas. El argumento principal que sustenta esta tesis es bastante sencillo porque en líneas generales plantea que la tesis es simplemente una síntesis de lo que dicen al respecto las concepciones estructuralista y la de van Fraassen, las cuales se consideran relativamente correctas. La tesis es una síntesis que recoge el punto donde ambas concepciones se refuerzan (la importancia de los modelos teóricos en la identidad de una teoría) y aquellos donde se complementan (la importancia de las aserciones empíricas, de acuerdo con van Fraassen, y la importancia de los modelos de datos en la identidad de una teoría, de acuerdo con los estructuralistas). Además se plantea que si bien estas dos concepciones coinciden (implícitamente) en cuanto a la importancia de estos tres elementos, existen diferencias en la manera como cada una de estas versiones caracteriza a cada uno de ellos, en especial los modelos de datos y la aserción empírica.

En síntesis, la tesis que se ha defendido es que dentro del enfoque semántico de las teorías los elementos determinantes en la individuación de una teoría son la clase propuesta de modelos teóricos, los modelos de datos y las aserciones empíricas. Pero con las siguientes importantes salvedades. (1) Un modelo es básicamente una estructura, de modo que la noción de modelo no equivale a la noción semántica, entendida en sentido estricto, como debe ser. (2) Los modelos de datos corresponden a una modelización de la experiencia, a una descripción estructural de la misma, pero un análisis estructural de las teorías no se compromete con una forma específica de caracterizar los modelos de datos; es decir, se deja abierta la cuestión de si los modelos de datos hay que caracterizarlos en función de o bien observables o bien términos T-no-teóricos o bien otros términos. ${ }^{8}$ (3) Algo semejante a lo anterior se defiende respecto a la aserción empírica: la forma general de una aserción empírica consiste en que relaciona un modelo de datos con un conjunto de modelos teóricos, pero un análisis estructural de las

Principia, 12(1) (2008), pp. 97-119. 
teorías no se compromete con una forma particular de dicha relación, ya sea de identidad o subsunción u otra. Todas estas condiciones básicamente plantean que la caracterización propuesta de las teorías científicas es neutral epistemológicamente, en los dos sentidos enunciados: en cuanto a que los tres elementos mencionados quedan caracterizados únicamente en términos estructurales, sin contener compromiso epistemológico alguno, y en cuanto al debate empirismorealismo. ${ }^{9}$

\section{Referencias}

Balzer, W.; Moulines, C. U.; Sneed, J. D. 1987. An Architectonic for Science: The Structuralist Program. Dordrecht: Reidel.

Balzer, W. \& Moulines, C. U. (eds.) 1996. Structuralist Theory of Science. Focal Issues, New Results. Berlin: Walter de Gruyter.

da Costa, N. 1997. El conocimiento científico. México: Universidad Nacional Autónoma de México, 2000.

Diederich, W. 1996. Structuralism As Developed Within the Model-Theoretical Approach in the Phlosophy of Science. In Balzer \& Moulines 1996.

Giere, R. N. 1988. Explaining Science. A Cognitive Approach. Chicago: University of Chicago Press.

Guerrero, G. 2000. Determinismo, modelos y modalidades. Revista de Filosofía 13(24): 191-216.

—. 2003. Enfoque semántico de las teorías. Estructuralismo y espacio de estados: coincidencias y divergencias. Tesis doctoral. Madrid: Universidad Complutense de Madrid (publicada en cd-rom).

—. 2007. van Fraassen y la concepción estructuralista de las teorías. Praxis Filosófica 25: 21-38.

Manzano, M. 1989. Teoría de Modelos. Madrid: Alianza.

Moulines, C. U. 1991a. Pragmatics in the Structuralist View of Science. In Schurz, G. \& Dorn, G. J. W. (eds.) Advances in Scientific Philosophy, Poznan Studies v. 24. Amsterdam: Editions Rodopi.

—. 1991b. Pluralidad y recursión. Estudios epistemológicos. Madrid: Alianza.

—. 1996. Structuralism: The Basic Ideas. In Balzer \& Moulines 1996.

—. 2002. Introduction: Structuralism as a Program for Modelling Theoretical Science. Synthese 130(1): 1-11.

Pérez-Ransanz, A. R. 1985. El concepto de teoría empírica según van Fraassen. Crítica 51(17): 3-12.

— 2000. La concepción semántica de las teorías y el debate sobre el realismo científico. In Ibarra, A. \& Mormann, T. Variedades de la representación en la ciencia y en la filosofía.

Principia, 12(1) (2008), pp. 97-119. 
Barcelona: Ariel, pp. 109-18.

Suppe, F. 1974. The Search for Philosophic Understanding of Scientific Theories. In Suppe, F. (ed) The Structure of Scienfific Theories. Urbana: University of Illinois Press.

- 1989. The Semantic Conception of Theories and Scientific Realism. Urbana: University of Illinois Press.

—. 2000. Understanding scientific theories: An assessment of developments, 19691998. Philosophy of Science 67 (Proceedings): S102-S115.

van Fraassen, Bas C. 1971. Semántica formal y Lógica. México: Universidad Nacional Autónoma de México, 1987.

—. 1980. The Scientific Image. Oxford: Clarendon Press.

-. 1985. On the Question of Identification of a Scientific Theory (A Reply to "van Fraassen's Concept of Empirical Theory" by Pérez Ransanz). Crítica 51(17): 21-5.

—. 1989. Laws and Symmetry. New York: Oxford University Press Inc.

1997. Structure and Perspective: Philosophical Perplexity and Paradox. In Dalla Chiara, M. L. et al. Logic and Scientific Methods. Synthese Library v. 259. Netherlands: Kluwer Academic Publishers.

\title{
Keywords
}

Theory, semantics approach, theoretic model, data model, empirical claim, van Fraassen.

\author{
Germán Guerrero Pino \\ Departamento de Filosofía \\ Universidad del Valle \\ Cali-Colombia \\ germangu@univalle.edu.co
}

\begin{abstract}
Resumo
Este trabalho defende a idéia que, de acordo com o enfoque semântico das teorias, há três elementos determinantes na identidade de uma teoria: a espécie de modelos teóricos, os modelos de dados e as asserções empíricas, mas com importantes exceções em cada caso. Para apoiar esta tese são analisadas as considerações sobre o assunto, respectivamente da concepção estruturalista das teorias e da concepção de van Fraassen.
\end{abstract}

\section{Palavras-chave}

Teoria, enfoque semântico, modelos teóricos, modelos de dados, asserções empíricas, van Fraassen.

Principia, 12(1) (2008), pp. 97-119. 


\section{Notas}

${ }^{1}$ En cuanto a los orígenes del enfoque semántico tenemos que si bien los trabajos pioneros en este nuevo tipo de análisis fueron realizados por Patrick Suppes a finales de la década de los cincuenta, su formulación sistemática inicial es de sólo hace treinta y cinco años con los aportes, por una parte, de Bastian C. van Fraassen, Frederick Suppe y Ronald Giere, en los E.U.A., que conforman una de las versiones del enfoque semántico; y, por otra parte, con los trabajos de Joseph D. Sneed (de E.U.A.), Wolfgang Stegmüller, Carlos Ulises Moulines y Wolfgang Balzer, en Europa, que conforman la otra versión influyente del enfoque semántico: la concepción estructuralista. B. C. van Fraassen y F. Suppe también fueron influenciados, además de por P. Suppes, por los trabajos en fundamentos de la mecánica cuántica de los matemáticos Hermann Weyl, John von Neumann y Birkhoff, y del lógico holandés Evert W. Beth.

2 Aquí, como en lo sucesivo, no empleó las expresiones que utilizan los estructuralistas ni, estrictamente, van Fraassen, sino que más bien hago uso de expresiones que me parecen más neutrales. Una justificación más completa de estos giros se presenta más adelante.

${ }^{3}$ Una exposición más extensa de estas dos concepciones la hago en Guerrero 2007.

${ }^{4}$ Este enfoque fue desarrollado principalmente por el positivismo lógico o empirismo lógico, en manos de filósofos de la ciencia como Rudolf Carnap, Hans Reichenbach, Ernest Nagel, Carl G. Hempel y otros; y además constituye la forma más elaborada de la concepción general de las teorías que podríamos decir: tuvo sus orígenes en el desarrollo del mismo pensamiento griego, más en concreto en el libro Elementos (300 a.c.) de Euclides; se consolidó al mismo tiempo que lo hacía la ciencia moderna en manos principalmente de Newton, más concretamente en su libro Principios Matemáticos de la Filosofía Natural (1687); y dominó además tanto la actividad científica como la reflexión filosófica hasta mediados del siglo XX. De modo que esta concepción en su forma general aún sigue considerándose como una respuesta viable a qué es una teoría científica, y de hecho podríamos decir que es la concepción dominante tanto en la ciencia como en la filosofía de la ciencia.

${ }^{5}$ Empleo "enunciado" en el sentido de la lógica formal, como "fórmula (bien formada) cerrada"; esto es, como "fórmula bien formada" en la que las variables están ligadas o no libres. Esto, desde el punto de vista de la gramática de un lenguaje natural como el castellano, equivaldría aproximadamente a "oración declarativa", aquella que es verdadera o falsa (véase van Fraassen 1971, p. 120).

${ }^{6}$ En mi escrito Guerrero 2000, hago una presentación más amplia del empirismo constructivo de van Fraassen contrastándolo con el realismo constructivo de Giere, el cual también se establece desde un enfoque semántico de las teorías.

${ }^{7}$ Este no es el espacio apropiado para ahondar en este asunto, remito a mi tesis doctoral (Guerrero 2003, pp. 132-7).

${ }^{8}$ En el presente escrito sólo se describe el contenido de esta tesis, pero se requiere de ar-

Principia, 12(1) (2008), pp. 97-119. 
gumentos adicionales a los aquí expuestos para que quede suficientemente bien sentada. Entre otras cosas, esto lo hago en mi tesis doctoral (Guerrero 2003).

${ }^{9}$ La principal tesis de este escrito la he desarrollado y sustentado en forma más extensa en mi tesis doctoral (Guerrero 2003), la cual adelanté bajo la dirección del profesor Javier Echeverrría Ezponda, Instituto de Filosofía del CSIC.

Principia, 12(1) (2008), pp. 97-119. 